\title{
RANCANG BANGUN SISTEM INFORMASI PEMANTAU TRANSPORTASI ZAT RADIOAKTIF DENGAN INPUT SMS TERENKRIPSI DAN NON-ENKRIPSI (STUDI KASUS: BATAN YOGYAKARTA)
}

\author{
Ferzha Putra Utama ${ }^{1}$, Kurnia Anggriani ${ }^{2}$, Yudi Setiawan ${ }^{3}$ \\ 1,2,3 Program Studi Teknik Informatika, Fakultas Teknik, Universitas Bengkulu \\ Jln. WR. Supratman Kandang Limun Bengkulu 38371.A \\ Tlp.(0736)344087 Ext.308; Fax.(0736)349134 \\ ${ }^{1}$ fputama@gmail.com \\ ${ }^{2}$ kurniaanggriani@gmail.com \\ ${ }^{1}$ ys.teknik@gmail.com
}

\begin{abstract}
Abstrak: Dalam pemanfaatan zat radioaktif, dimungkinkan untuk ditransportasikan dari satu tempat ke tempat lain. Keselamatan transportasi zat radioaktif harus dipantau secara berkala dengan cara memberikan informasi bahwa zat tidak mengalami kebocoran selama di perjalanan. Penelitian ini membahas tentang rancang bangun sebuah sistem informasi geografis pemantau transportasi zat radioaktif berbasis web atau disebut Control Room Module (CRM). Sistem informasi ini akan menerima data berupa SMS terenkripsi yang dikirim secara periodik dari sistem pemantau zat radioaktif yang terletak pada kendaraan pembawa yang dinamakan In Vehicles Module (IVM). SMS terenkripsi tersebut akan diolah menjadi informasi berupa peta digital, data dalam tabel, dan grafik. Informasi tersebut akan membantu pihak pengambil keputusan untuk memprediksi perubahan nilai paparan zat radioaktif dan apabila terjadi kebocoran selama transportasi, dapat diambil keputusan dengan segera. Setelah dilakukan pengujian, CRM tidak tepat menerima data setiap 1 menit sekali, namun dengan rata-rata jarak penerimaan 80,341 detik. Selain itu pada saat pemantauan menggunakan 2 IVM secara bersamaan, CRM membutuhkan waktu proses dekripsi rata-rata 0,4 detik lebih lama dibandingkan dengan hanya menggunakan 1 IVM.

Kata Kunci: Sistem informasi, pemantau, zat radioaktif, enkripsi-dekripsi, SMS terenkripsi.
\end{abstract}

Abstract: In the utilization of a radioactive substance, possible to transported it from one place to another. Transport safety of radioactive substances must be monitored regularly by providing information that a substance not leak during the transshipment. This research talked about a design of geographic information system based on web for monitoring transportation of radioactive substance or can be called as Control Room Module (CRM). The information systems will receive encrypted SMS that sent periodically by a monitoring system of radioactive substance, called In Vehicles Module (IVM) that located on vehicle carrier. Encrypted SMS will be processed to be information in the form of digital map, data in table, and charts. The information will assist the decision makers to predict change the value of radioactive substances exposure and in case of leakage during transportation, a decision can be taken immediately. The testing result shows a difference in the periode of incoming SMS, instead of 1 minute periode, the average measure of the periode is 80.341 seconds. The testing also shows different time computation between monitoring 1 IVM and more than 1 IVMs. The average time for 2 IVM decryption is 0,4 seconds longer than that of for 1 IVM.

Keywords: Information sistem, monitoring, radioactive substance, encryption-decryption, encrypted SMS. 
Jurnal Pseudocode, Volume II Nomor 2, September 2015, ISSN 2355 - 5920

\section{PENDAHULUAN}

Zat radioaktif merupakan sumber energi yang potensial. Zat radioaktif dapat dimanfaatkan sebagai pembangkit listrik, teknologi pertanian, bidang kesehatan, dan lain sebagainya. Zat radioaktif merupakan bahan atau zat yang mengandung inti atom tidak stabil, dalam UU No.10/1997 Pasal 1 ayat 9 mengatakan, zat radioaktif adalah setiap zat yang memancarkan radiasi pengion dengan aktivitas jenis lebih besar dari $\quad 70 \quad \mathrm{kBq} / \mathrm{kg} \quad(2 \quad \mathrm{nCi} / \mathrm{g}) \quad[1] . \quad$ Dalam pemanfaatannya, zat radioaktif memungkinkan untuk dipindahkan dari satu tempat ke tempat lain untuk kepentingan tertentu oleh pihak yang berkepentingan atau yang berwenang. Zat radioaktif berpotensi mengalami kecelakaan atau kebocoran pada saat dimanfaatkan atau pada saat proses pendistribusiannya. Pendistribusian zat radioaktif perlu dipantau agar apabila terjadi kecelakaan yang dapat menimbulkan radiasi di atas ambang normal, pihak pengambil keputusan dapat segera mengetahui dan dapat melakukan tindakan pengamanan.

Sistem informasi geografis dapat diaplikasikan dalam berbagai bidang, salah satunya pemantau transportasi zat radioaktif. Penelitian ini bertujuan untuk mengembangkan sistem informasi pemantau transportasi zat radioaktif berbasis web yang dapat menerima data SMS terenkripsi dari titik-titik pemantauan secara real-time yang diolah menjadi informasi yang akurat. Sistem pemantau transportasi zat radioaktif ini terdiri dari dua sub sistem, yaitu sistem pemantau zat radioaktif yang berupa seperangkat alat yang dilengkapi detektor zat radioaktif dan GPS yang diletakkan pada kendaraan pembawa zat radioaktif (titik pemantauan) yang dinamakan dengan In Vehicle Module (IVM) dan sistem informasi geografis berbasis web yang menerima dan mengolah data monitoring yang dikirimkan IVM menjadi informasi, sistem informasi ini dinamakan Control Room Module (CRM) [2].

Hasil monitoring yang dikirimkan oleh IVM adalah SMS terenkripsi, tujuannya adalah agar informasi yang terkandung dalam SMS tersebut tidak mudah terjemahkan pihak yang tidak berhak. Hasil monitoring tersebut memerlukan proses dekripsi untuk mendapatkan informasi asli. Untuk melakukan dekripsi data SMS terenkripsi yang dikirim dari IVM, akan dilakukan beberapa tahapan sehingga didapat informasi asli mengenai transportasi zat radioaktif.

Informasi yang akan ditampilkan oleh sistem informasi adalah berupa peta perjalanan (transportasi) zat radioaktif berbasis Google Maps, data dalam bentuk tabular, dan grafik perjalanan. Sistem ini akan memberikan informasi peringatan apabila terjadi kebocoran zat radioaktif dalam perjalanan agar dapat dilakukan tindakan tepat oleh pihak yang berwenang. Sistem informasi juga akan bersifat rahasia, artinya hanya pihak yang berkepentingan yang dapat masuk ke dalam sistem (login), seperti BATAN (Badan Tenaga Nuklir Nasional) yang menyediakan zat radioaktif secara legal.

\section{TINJAUAN SISTEM}

Sistem informasi (CRM) yang dirancang akan menggunakan algoritme hybrid, yaitu penggunaan dua algoritme kriptografi dalam melakukan dekripsi SMS. Data yang dikirimkan dari IVM ke CRM adalah berupa SMS yang telah dienkripsi dengan algoritme Vigenere dan Vernam [3]. Algoritme Vigenere yang digunakan telah dimodifikasi dari Vigenere karakter alfabetis menjadi karakter numeris, hal ini dikarenakan data laju paparan radiasi, posisi, dan waktu berkarakter numeris [4]. Untuk mendapatkan kunci publik 
yang unik pada setiap SMS yang diterima, sistem menggunakan algoritme Vernam yang mengadopsi algoritme OTP (One-Time Pad) yang membangkitkan deretan karakter kunci (pad) secara acak. Setiap kunci hanya akan digunakan satu kali, kemudian dihancurkan agar tidak digunakan kembali untuk pesan yang lain [5]. Dengan kata lain setiap SMS akan dienkripsi dan didekripsi dengan kunci yang berbeda dengan SMS lainnya.

Fokus dari penelitian ini adalah untuk mengembangkan sebuah sistem informasi geografis untuk memantau transportasi zat radioaktif. Proses kerja sistem yang akan dirancang, digambarkan dengan flowchart pada Gambar 1. Proses dimulai dari penerimaan SMS terenkripsi yang dikirimkan dari IVM (In Vehicle Module) ke CRM (Control Room Module). Selanjutnya data tersebut akan didekripsi menjadi plaintext (pesan asli) pada sistem dan disimpan ke dalam database. Selanjutnya data pada database akan diekstrak atau diidentifikasi untuk memisahkan data waktu, posisi (koordinat), dan data paparan. Kemudian pengguna sistem dapat menampilkan data transportasi dalam bentuk peta, tabel dan grafik. Apabila pada saat transportasi berlangsung terjadi paparan zat radioaktif di atas ambang batas (kebocoran) yang ditentukan, sistem akan memberikan peringatan berupa alarm pada peta dan pihak pengambil keputusan dapat melakukan tindakan pengamanan pada lokasi kebocoran. Namun jika tidak terjadi kebocoran hingga zat radioaktif sampai ke lokasi tujuan, pemantauan telah selesai dilakukan. Sistem informasi ini akan menampilkan dan memperbaharui informasi transportasi secara periodis berdasarkan SMS yang dikirimkan IVM. Untuk menjelaskan skenario sistem pemantau pemantau transportasi zat radioaktif yang terdiri dari IVM dan CRM digambarkan dengan blok diagram pada Gambar 2.

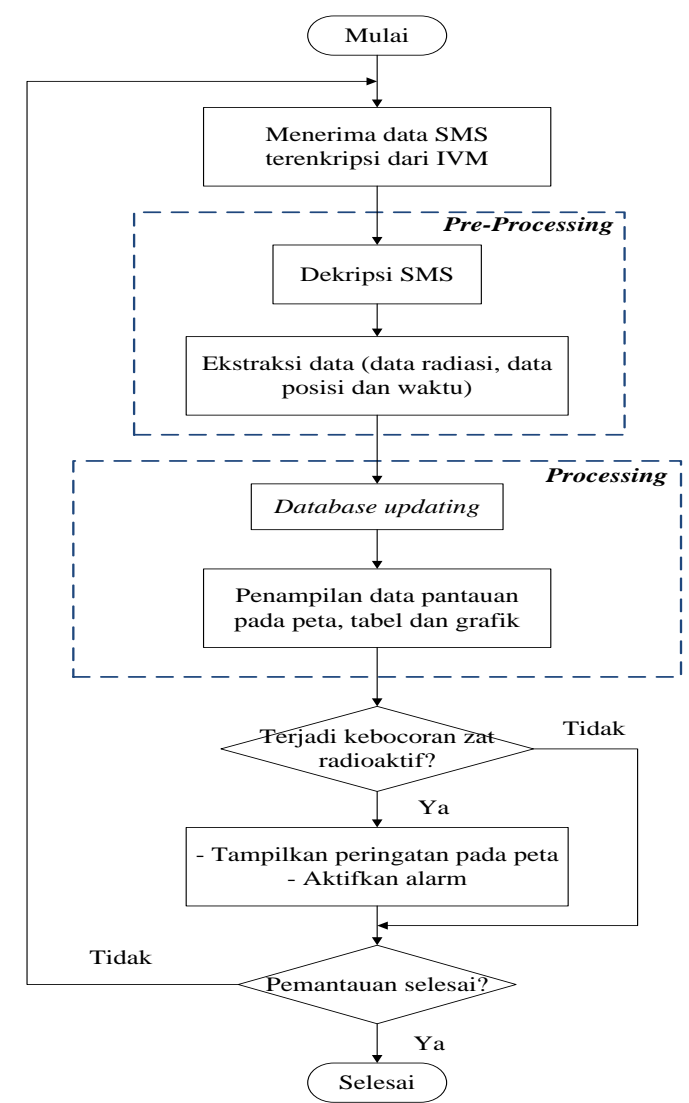

Gambar. 1 Flowchart sistem kerja CRM

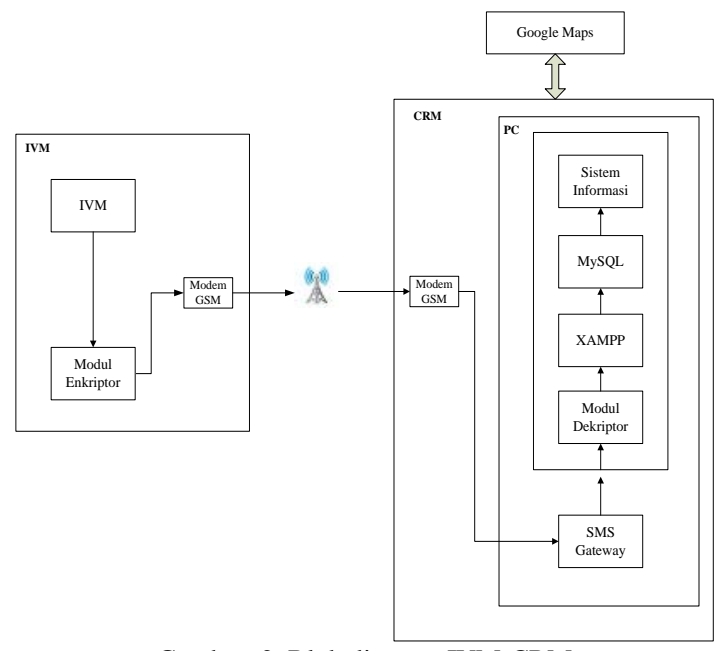

Gambar. 2 Blok diagram IVM-CRM

\section{DESAIN PERANGKAT LUNAK}

Data yang diterima CRM dari IVM merupakan SMS terenkripsi yang perlu didekripsi terlebih dahulu kemudian diidentifikasi dengan 
Jurnal Pseudocode, Volume II Nomor 2, September 2015, ISSN 2355 - 5920

memisahkan informasi-informasi yang dibawa oleh pesan terdekripsi (pesan asli). Berikut ini adalah penjelasan mengenai proses penerimaan pesan, dekripsi dan identifikasi SMS.

\section{A. Penerimaan Data SMS Terenkripsi}

Sebagai bahan dasar dari informasi yang ditampilkan pada sistem informasi pemantau transportasi zat radioaktif, SMS terenkripsi dari IVM merupakan data utama yang digunakan. Data tersebut akan diterima oleh CRM dengan menggunakan modem GSM sebagai alat penerima data. Untuk menghubungkan IVM dengan CRM dalam proses penerimaan data, sistem pada CRM membutuhkan SMS Gateway [6]. Setelah data diterima oleh CRM, data tersebut akan masuk ke dalam database pada tabel inbox sebelum dilakukan proses dekripsi.

\section{B. Proses Dekripsi Data SMS}

IVM dirancang untuk melakukan enkripsi pesan sedemikian rupa agar pesan yang dikirimkan ke CRM aman. Proses dekripsi SMS terenkripsi akan dilakukan apabila data tersebut telah masuk ke dalam tabel inbox, setelah dilakukan dekripsi maka data terdekripsi tersebut akan disimpan ke dalam tabel pesan pada database. Pada proses dekripsi data, langkah selanjutnya yang dilakukan yaitu dengan mengenali nomor GSM pengirim pesan yang telah didaftarkan pada sistem, apabila nomor GSM tidak dikenali (tidak terdaftar), maka pesan hanya dapat masuk ke database (tabel inbox) namun tidak diproses lebih lanjut, misalnya seperti SMS promo dari operator GSM. Format SMS yang dapat didekripsi juga telah ditentukan sebelumnya, yaitu pesan yang berbentuk angka yang diawali dengan karakter header (*) dan diakhiri dengan karakter end (\#).
Konten SMS yang dikirim IVM berjumlah 72 atau 74 karakter angka tergantung dengan informasi yang dibawanya, ditambah lagi dengan dua karakter * dan \# sebagai penanda. Pada dasarnya, pesan yang telah dipisahkan dari header dan end terdiri dari dua bagian, yaitu bagian setengah awal adalah angka yang mengandung kunci publik (public cipher) dan bagian setengah akhir adalah pesan terenkripsi (data serial cipher) yang berisi informasi zat radioaktif yang terdiri dari waktu, tanggal, koordinat dan nilai paparan radiasi.

Untuk langkah mendekripsi pesan terenkripsi yang diterima, proses yang pertama dilakukan adalah memisahkan penanda kemudian menghitung panjang pesan atau banyaknya karakter angka lalu dibagi menjadi dua bagian. Dalam mendekripsi pesan terenkripsi tersebut, CRM membutuhkan private key yang sama persis dengan private key digunakan oleh IVM dalam mengenkripsi pesan asli. Private key kemudian digunakan untuk mendekripsi public cipher atau bagian setengah awal pesan terenkripsi untuk mendapatkan kunci publik. Kunci publik yang telah didapatkan akan berbeda-beda karena dienkripsi dengan algoritme penyandian Vernam yang hanya akan menghasilkan kunci sekali pakai [7]. Kunci publik tersebut kemudian akan digunakan sebagai kunci untuk mendapatkan pesan asli yang terenkripsi pada bagian setengan akhir (data serial cipher). Proses penerimaan dan dekripsi SMS terenkripsi dapat ditunjukkan dengan flowchart pada Gambar 3.

\section{Identifikasi Data SMS}

Data SMS terenkripsi yang telah diterima oleh CRM dari IVM akan didekripsi hingga didapat pesan asli. Pesan asli memiliki informasi waktu, tanggal, koordinat, dan nilai paparan radiasi zat 
radioaktif. Agar informasi yang dibawa pesan asli dapat terlihat lebih jelas fungsinya, maka perlu dilakukan identifikasi dengan memisahkan setiap informasi. Sebuah pesan asli memiliki format hhmmssddbbttLLLLLLLLBBBBBBBBBlljj, untuk lebih jelas dapat dilihat pada Tabel 1.

Posisi Lintang dan Bujur yang ada pada pesan asli yang diterima adalah dalam format kode ASCII. Berdasarkan tabel kode ASCII, nilai 83 adalah S (South) yang menyatakan Lintang Selatan dan nilai 69 adalah E (East) yang menyatkan Bujur Timur. Sedangkan untuk Nilai Paparan zat radioaktif, merupakan nilai pecahan dengan nilai maksimal 99,99 dalam satuan mR/jam (milliRoentgens per jam).

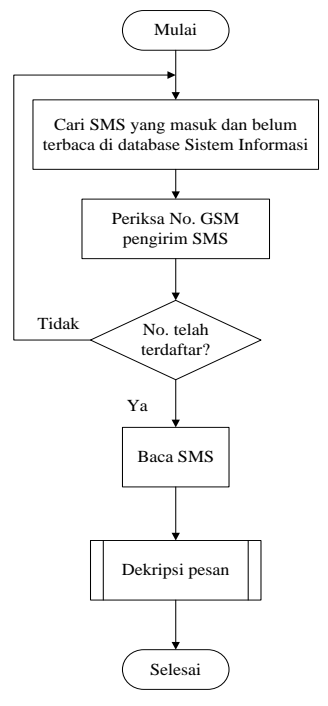

(a)

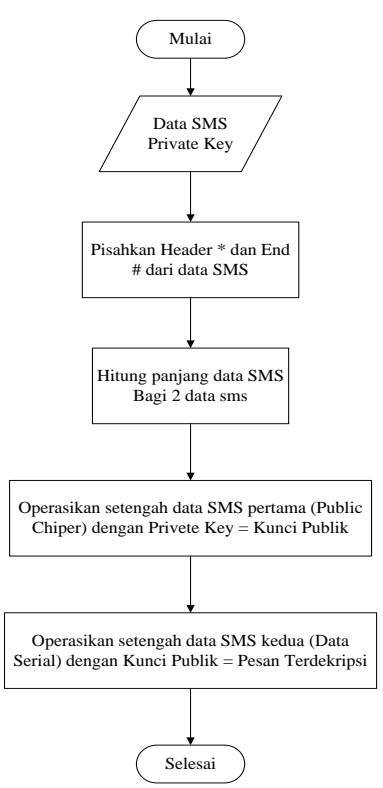

(b)
Gambar. 3 (a) Flowchart proses penerimaan SMS terenkripsi

(b) Flowchart proses dekripsi SMS terenkripsi

Tabel 1. Identifikasi Pesan Asli

\begin{tabular}{|l|l|l|}
\hline No. & \multicolumn{1}{|c|}{ Data } & \multicolumn{1}{c|}{ Panjang Data } \\
\hline 1. & Jam & hh (2 digit) \\
\hline 2. & Menit & mm (2 digit) \\
\hline 3. & Detik & ss (2 digit) \\
\hline 4. & Tanggal & dd (2 digit) \\
\hline 5. & Bulan & bb (2 digit) \\
\hline 6. & Tahun & tt (2 digit) \\
\hline
\end{tabular}

\begin{tabular}{|l|l|l|}
\hline 7. & $\begin{array}{l}\text { Koordinat } \\
\text { Lintang }\end{array}$ & LLLLLLLL (8 digit) \\
\hline 8. & Koordinat Bujur & BBBBBBBBB (9 digit) \\
\hline 9. & Posisi Lintang & ll (2 digit) \\
\hline 10. & Posisi Bujur & jj (2 digit) \\
\hline 11. & Nilai Paparan & pppp (3 sampai 4 digit) \\
\hline
\end{tabular}

Koordinat yang dibawa oleh pesan asli merupakan koordinat dalam format derajat (degree) dan menit (minutes) atau disebut juga dengan koordinat MinDec. Format koordinat ini adalah derajat menit koma menit (dd mm.mmmm). Tanda minus (-) pada koordinat lintang menunjukkan Selatan (South) dan tanda (+) menunjukkan Utara (North). Koordinat dengan format derajat menit (MinDec) yang ada pada pesan asli perlu diubah lagi menjadi format derajat desimal (DegDec). Hal ini perlu dilakukan agar koordinat dapat ditunjukkan dengan benar pada peta Google Maps, karena Google Maps menggunakan koordinat berformat derajat desimal [8].

\section{Pemodelan Sistem}

Untuk menjelaskan bagaimana hubungan yang terjadi antara pengguna dengan sistem informasi dan sistem informasi dengan IVM, maka akan dimodelkan dengan diagram Use Case pada Gambar 4. Use Case pada Gambar 4 menjelaskan interaksi antara aktor yang terlibat di dalam sistem informasi, yaitu:

Pengunjung: Dapat melakukan login apabila terdaftar sebagai Pengunjung. Aktor ini hanya dapat melihat peta dan tabel perjalanan zat radioaktif yang dipesannya.

Administrator: Dapat melakukan login apabila terdaftar sebagai Admin. Aktor ini dapat melihat seluruh peta, tabel, dan grafik perjalanan zat radioaktif. Admin dapat meng-input atau meng- 
update data pengunjung, perjalanan zat radioaktif, IVM, melihat arsip peta dan tabel.

Supervisor: Dapat melakukan login, melihat semua peta, tabel, dan grafik perjalanan zat radioaktif. Supervisor dapat meng-input atau meng-update data Administrator. Supervisor juga dapat melihat semua arsip peta dan tabel.

IVM: Aktor ini merupakan mesin yang mengirimkan data SMS terenkripsi ke sistem informasi (CRM).

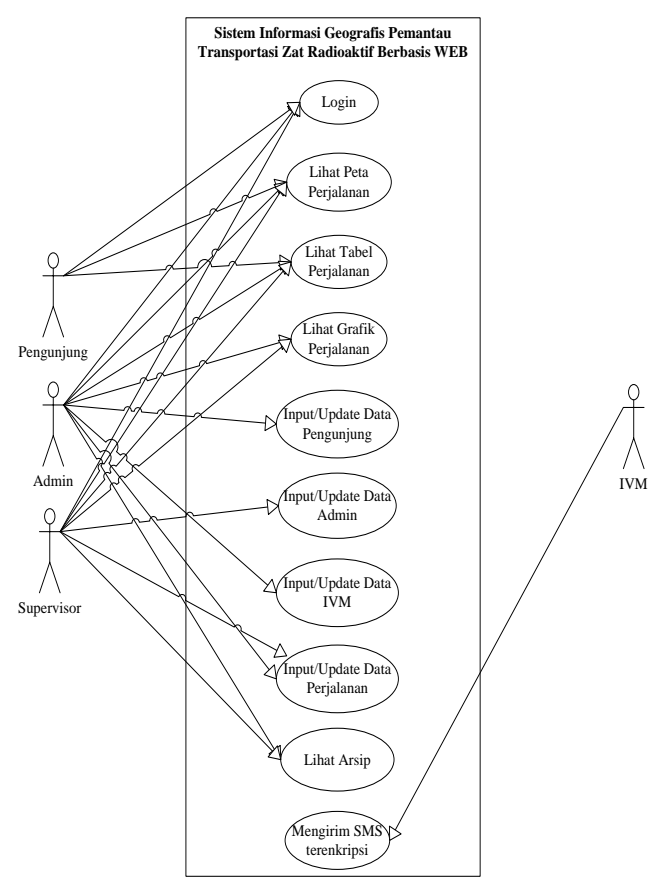

Gambar. 4 Use case diagram CRM

\section{Perancangan Database}

Terdapat lima tabel pada database yang dirancang untuk sistem informasi geografis pemantau transportasi zat radioaktif yang terdiri dari tabel user, tabel IVM, tabel pesan, tabel perjalanan, dan tabel inbox. Dalam pemodelan struktur data dan hubungan antara tabel pada database sistem informasi geografis pemantau zat radioaktif digunakan Entity Relationship Diagram (ERD) pada Gambar 5.

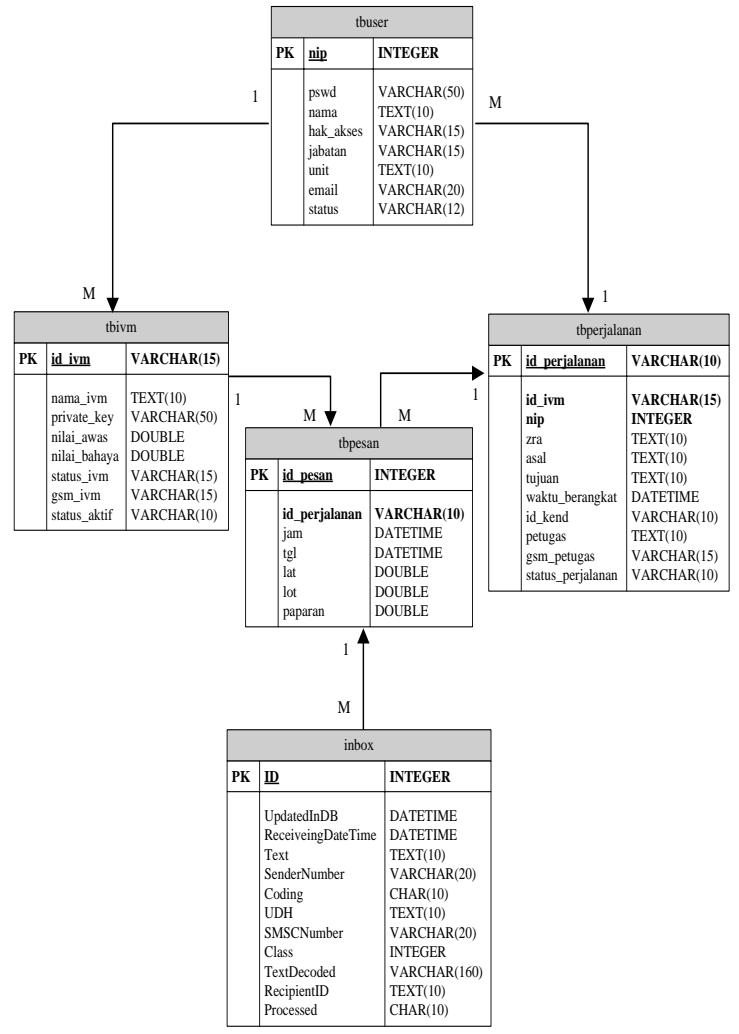

Gambar. 5 Entity Relationship Diagram (ERD) CRM

\section{PENGUJian DAN HASIL}

\section{A. Pengujian}

Pengujian dilakukan dengan membawa IVM dengan kendaraan bermotor beserta dengan zat radioaktif beradiasi rendah, dalam pengujian ini menggunakan kaos lampu petromaks sebagai zat radioaktif. Pengujian sistem dilakukan sebanyak enam kali, dengan IVM yang di-setting untuk mengirimkan SMS secara periodik 1 menit sekali. Pengujian 1 sampai 4 dilakukan untuk menguji waktu terima SMS dari IVM dengan menggunakan 2 provider GSM IVM dan pada waktu yang berbeda. Pengujian kelima dan keenam dilakukan untuk melihat waktu proses dekripsi saat memantau lebih dari 1 IVM, pengujian kelima menggunakan 1 IVM dan keenam menggunakan 2 IVM (terenkripsi dan tanpa enkripsi). Statistik rata-rata jarak waktu penerimaan SMS pada pengujian 1 hingga 4 ditunjukkan pada Tabel 2 
dan perbandingan standar deviasi keempat pengujian tersebut ditunjukkan pada Tabel 3.

Tabel 2. Rata-rata jarak waktu penerimaan SMS pegujian 1 hingga 4

\begin{tabular}{|c|c|c|}
\hline \multirow{2}{*}{ Waktu } & \multicolumn{2}{|c|}{$\begin{array}{c}\text { Rata-rata Jarak Waktu Terima } \\
\text { SMS }\end{array}$} \\
\cline { 2 - 3 } & Provider A (detik) & $\begin{array}{c}\text { Provider } \\
\text { B (detik) }\end{array}$ \\
\hline Siang & 69,071 & 79,384 \\
\hline Malam & 95,636 & 77,272 \\
\hline Jumlah Per Provider & 164,707 & 156,656 \\
\hline Jumlah Keseluruhan & \multicolumn{2}{|c|}{321,363} \\
\hline Rata-rata & \multicolumn{2}{|c|}{80,341} \\
\hline
\end{tabular}

Tabel 3. Perbandingan standar deviasi pengujian 1 hingga 4

\begin{tabular}{|c|c|c|}
\hline \multirow{2}{*}{ Waktu } & \multicolumn{2}{|c|}{ Standar Deviasi Data Pengujian } \\
\cline { 2 - 3 } & Provider A (detik) & Provider B (detik) \\
\hline Siang & 0,9972 & 33,5448 \\
\hline Malam & 35,1376 & 1,1908 \\
\hline
\end{tabular}

Dari pengujian kelima dengan menggunakan 1 IVM terenkripsi, menghasilkan 30 data SMS. Jumlah waktu dan rata-rata proses terima SMS serta waktu proses dekripsi pada CRM ditunjukkan pada Tabel 4 dan data secara grafik pada Gambar 6.

Tabel 4. Waktu proses SMS pada pengujian kelima

\begin{tabular}{|c|c|c|}
\hline Jumlah & $\begin{array}{c}\text { Waktu Proses } \\
\text { Terima }\end{array}$ & $\begin{array}{c}\text { Waktu Proses } \\
\text { Dekripsi }\end{array}$ \\
\hline Dalam Menit & $00: 10: 46$ & $00: 05: 25$ \\
\hline Dalam Detik & 646 & 325 \\
\hline Rata-rata (detik) & 21,533 & 10,833 \\
\hline
\end{tabular}

Pada pengujian keenam dilakukan 2 transportasi secara bersamaan dengan menggunakan 1 IVM terenkripsi dan 1 IVM tanpa enkripsi. Kedua transportasi menghasilkan masing-masing 30 data. Untuk IVM tanpa enkripsi tidak terdapat proses dekripsi namun hanya proses identifikasi untuk memisahkan data waktu, koordinat, dan nilai paparan zat radioaktif yang terkandung dalam data SMS. Data jumlah waktu proses terima SMS terdekripsi dan waktu proses identifikasi pada CRM untuk IVM tanpa enkripsi ditunjukkan pada Tabel 5 dan grafik pada Gambar 7.
Waktu Proses Terima dan Dekripsi SMS

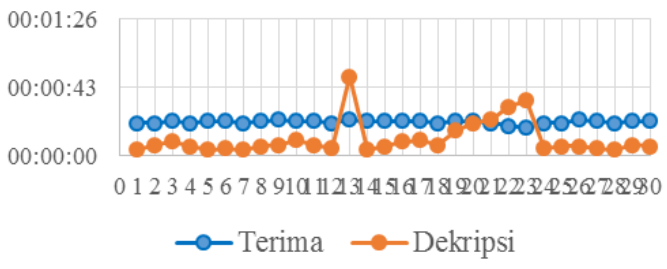

Gambar. 6 Grafik proses terima dan dekripsi pengujian kelima Tabel 5. Waktu proses SMS tanpa enkripsi pengujian keenam

\begin{tabular}{|c|c|c|}
\hline Jumlah & $\begin{array}{c}\text { Waktu Proses } \\
\text { Terima }\end{array}$ & $\begin{array}{c}\text { Waktu Proses } \\
\text { Identifikasi }\end{array}$ \\
\hline Dalam Menit & $00: 10: 49$ & $00: 05: 30$ \\
\hline Dalam Detik & 649 & 330 \\
\hline Rata-rata (detik) & 21,633 & 11 \\
\hline
\end{tabular}

Waktu Proses Terima dan Identifikasi SMS

00:01:26
를 $00: 00: 43$
$00: 00: 00$ $\begin{array}{lllllllllll}1 & 3 & 5 & 7 & 9 & 11 & 13 & 1517192123252729\end{array}$ $\underset{\sim}{-T e r i m a} \stackrel{\text { Data }}{\rightarrow}$ Identifikasi

Gambar. 7 Grafik proses terima dan identifikasi pengujian keenam

Sedangkan data pengujian keenam dengan menggunakan IVM terenkripsi ditunjukkan Tabel 6 dan grafik pada Gambar 8.

Tabel 6. Waktu proses SMS terenkripsi pengujian keenam

\begin{tabular}{|c|c|c|}
\hline Jumlah & $\begin{array}{c}\text { Waktu Proses } \\
\text { Terima }\end{array}$ & $\begin{array}{c}\text { Waktu Proses } \\
\text { Dekripsi }\end{array}$ \\
\hline Dalam Menit & $00: 14: 42$ & $00: 05: 37$ \\
\hline Dalam Detik & 882 & 337 \\
\hline $\begin{array}{c}\text { Rata-rata } \\
\text { (detik) }\end{array}$ & 29,4 & 11,233 \\
\hline
\end{tabular}

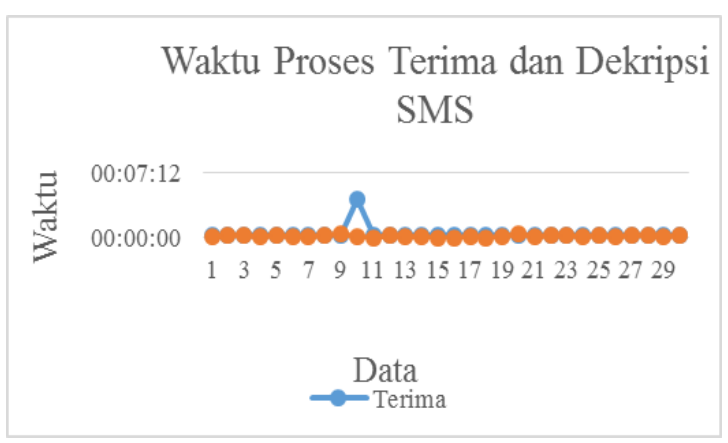

Gambar. 8 Grafik proses terima dan dekripsi pengujian keenam 
Kemudian untuk mengetahui perbedaan waktu proses terima dan proses dekripsi pada pengujian kelima dan keenam, dilakukan perbandingan data yang dihasilkan oleh IVM terenkripsi pada pengujian kelima dan keenam yang ditunjukkan pada Tabel 7.

Tabel 7. Perbandingan waktu proses data pengujian kelima dan keenam

\begin{tabular}{|l|c|c|}
\hline Transportasi & $\begin{array}{c}\text { Rata-rata waktu } \\
\text { proses terima } \\
\text { (detik) }\end{array}$ & $\begin{array}{c}\text { Rata-rata waktu } \\
\text { proses dekripsi } \\
\text { (detik) }\end{array}$ \\
\hline Kelima & 21,533 & 10,833 \\
\hline Keenam & 29,4 & 11,233 \\
\hline Selisih & 7,867 & 0,4 \\
\hline
\end{tabular}

\section{B. Hasil}

Setelah dilakukan analisis dan perancangan, maka sistem informasi dapat diaplikasikan menjadi sebuah sistem informasi pemantau transportasi zat radioaktif berbasis web. Berikut ini akan ditampilkan beberapa fitur yang dapat dilakukan oleh CRM.

1) Halaman Peta Perjalanan: Pada halaman Peta Perjalanan akan menampilkan jalur transportasi zat radio aktif secara real-time. Pada halaman ini juga terdapat tabel yang menampilkan data update perjalanan yang sedang berlangsung, serta memberikan informasi kepada pengambil keputusan apabila terjadi kebocoran zat radioaktif. Informasi kebocoran pada peta disimbolkan dengan icon berwarna kuning untuk status awas, merah untuk status bahaya, sedangkan jika berwarna hijau zat radioaktif dalam keadaan aman. Pada tabel, informasi tersebut ditandai dengan warna kolom hijau, kuning dan merah. Namun kerena zat radioaktif yang digunakan memiliki paparan radiasi yang kecil, sehingga dalam penelitian ini tidak terjadi paparan di atas batas normal. Tampilan halaman Peta Perjalanan ditunjukkan pada Gambar 9.

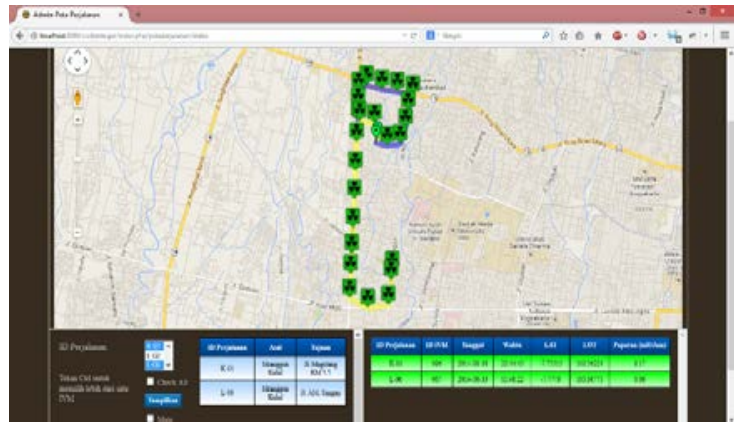

Gambar. 9 Tampilan halaman Peta Perjalanan

2) Halaman Tabel Perjalanan: Halaman Tabel Perjalanan menampilkan data perjalanan secara keseluruhan yang dikelompokkan berdasarkan ID Perjalanan yang dipilih. Tampilan halaman Tabel Perjalanan ditunjukkan pada Gambar 10.

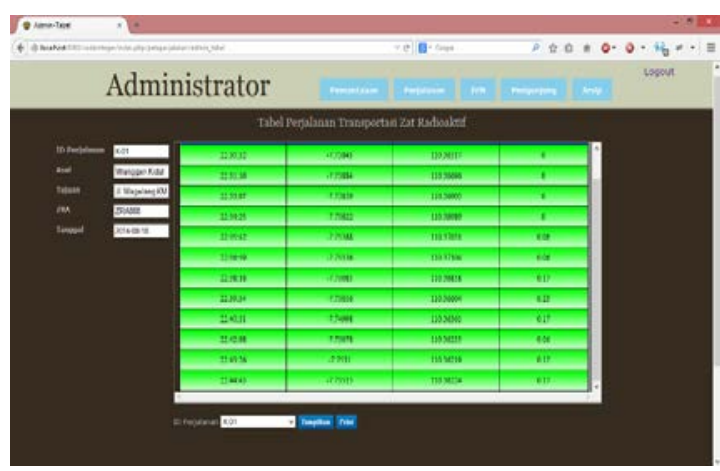

Gambar. 10 Tampilan halaman Tabel Perjalanan

3) Halaman Grafik Perjalanan: Halaman Grafik Perjalanan berguna bagi pihak pengambil keputusan untuk memprediksi perubahan zat radioaktif berdasarkan pola yang ditunjukkan oleh grafik ini. Grafik dilengkapi dengan nilai batas yang merupakan perubahan nilai paparan yang masih dalam kondisi aman. Nilai aman ini merupakan kondisi ideal bagi zat radioaktif, tanpa dipengaruhi oleh faktor dari luar, seperti laju angin, sinar matahari, dan guncangan. Tampilan halaman Grafik Perjalanan ditunjukkan pada Gambar 11. 


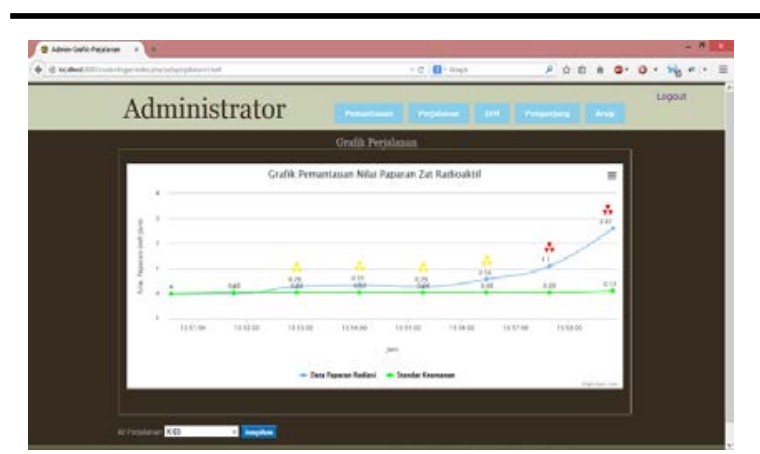

Gambar. 11 Tampilan halaman Grafik Perjalanan

4) Halaman Arsip Perjalanan: Halaman Arsip Perjalanan berguna bagi Administrator dan Supervisor untuk mengetahui perjalanan yang telah selesai dilakukan Halaman arsip perjalanan dapat menampilkan arsip perjalanan dalam bentuk peta, tabel, dan data dalam format pdf. Gambar 12 menunjukkan tampilan halaman Arsip Perjalanan.

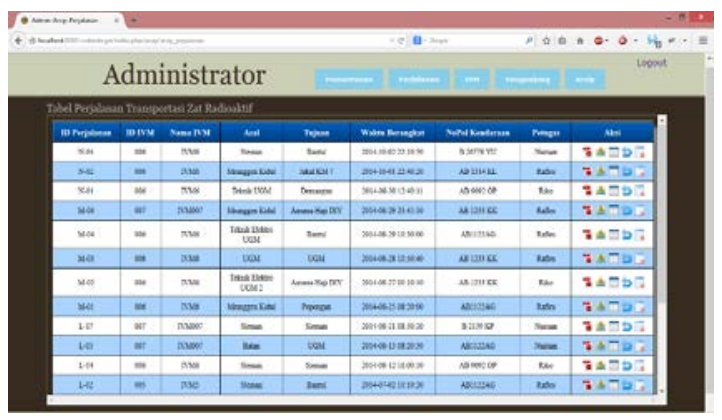

Gambar. 12 Tampilan halaman Arsip Perjalanan

5) Statistik Pengujian: Berdasarkan statistik pengujian yang dilakukan, IVM di-setting untuk mengirimkan SMS secara periodik setiap 1 menit sekali. Pada pengujian 1 hingga 4 menghasilkan waktu terima rata-rata data 80,341 detik atau tidak tepat 1 menit sekali. Hal ini dapat dikarenakan oleh beberapa faktor, seperti waktu komputasi yang diperlukan IVM untuk mengenkripsi SMS dan proses pengiriman SMS yang dapat dipengaruhi oleh kepadatan lalu lintas operator GSM yang terdapat pada IVM. Pengujian kelima dan keenam menunjukkan bahwa terdapat selisih waktu pada kedua pengujian. Pengujian keenam dengan menggunakan 2 IVM rata-rata lebih lama 7,867 detik untuk menerima data dan rata-rata lebih lama 0,4 detik untuk melakukan proses dekripsi dibandingkan dengan pengujian kelima.

\section{UCAPAN TERIMA KASIH}

Terimakasih kepada Bapak I Wayan Mustika, S.T., M.Eng., Ph.D., Ibu Ir. Litasari, M.Sc., dan Mas Adi Abimanyu, S.T., M.Eng. atas bimbingan dan bantuan selama pengerjaan penelitian ini.

\section{REFERENSI}

[1] "UU Ketenaganukliran," in Pasal 1 ayat 9, ed. Indonesia, 1997.

[2] Purwantoro, "Sistem Informasi Pemantau Pengangkutan Zat Radioaktif Berbasis Google Maps," Elektronika Instrumentasi, STTN Yogyakarta, Yogyakarta, 2013.

[3] N. Adi Abimanyu, Jumari, "Implementasi Algoritma Vigenere Menggunakan Mikrokontroler Untuk Pengiriman SMS Pada Sistem Pemantau Pengangkutan Zat Radioaktif," Prosiding Seminar 2013.

[4] A. Abimanyu, "Rancang Bangun Sistem Pemantau Pengangkutan Zat Radioaktif Menggunakan SMS Tersandi," Program Pascasarjana Jurusan Teknik Elektro dan Teknologi Informasi Fakultas Teknik, Universitas Gadjah Mada, Yogyakarta, 2014.

[5] R. Munir, "Algoritma Enkripsi Citra dengan Pseudo OneTime Pad yang Menggunakan Sistem Chaos," KNIF, 2011.

[6] R. R. I. Raidah Hanifah, Yuli Christyono, "Simulasi Sistem Informasi Geografis (SIG) Pemantauan Posisi Kendaraan Via SMS Gateway," Online Jurnal TRANSMISI, pp. 45-49, 2010.

[7] D. Ariyus, Kriptografi Keamanan Data dan Komunikasi. Yogyakarta: Graha Ilmu, 2006.

[8] D. P. Dhimas Novergust, Taufiqurrahman, "Sistem Online Untuk Keamanan dan Pelacakan Kendaraan Menggunakan GPS Tracker dan Google Map," Politeknik Elektronika Negeri Surabaya 2012. 